\title{
Cellular events during sexual development from amoeba to plasmodium in the slime mould Physarum polycephalum
}

\author{
Juliet Bailey, ${ }^{1 *}$ Roger W. ANDerson ${ }^{2}$ and Jennifer DeE ${ }^{1}$ \\ ${ }^{1}$ Department of Genetics, University of Leicester, University Road, Leicester LE1 7RH, UK \\ 2 Department of Molecular Biology and Biotechnology, University of Sheffield, Sheffield S10 2TN, UK
}

(Received 11 August 1989; revised 10 November 1989; accepted 8 December 1989)

\begin{abstract}
Time-lapse cinematography and immunofluorescence microscopy were used to study cellular events during amoebal fusions and sexual plasmodium development in Physarum polycephalum. Amoebal fusions occurred frequently in mixtures of strains heteroallelic or homoallelic for the mating-type locus mat $A$, but plasmodia developed only in the mat $A$-heteroallelic cultures. These observations confirmed that mat $A$ controls development of fusion cells rather than cell fusion. Analysis of cell pedigrees showed that, in both types of culture, amoebae fused at any stage of the cell cycle except mitosis. In mat $A$-heteroallelic fusion cells, nuclear fusion occurred in interphase about $\mathbf{2} \mathrm{h}$ after cell fusion; interphase nuclear fusion did not occur in $\mathbf{m a t} A$-homoallelic fusion cells. The diploid zygote, formed by nuclear fusion in mat $A$-heteroallelic fusion cells, entered an extended period of cell growth which ended in the formation of a binucleate plasmodium by mitosis without cytokinesis. In contrast, no extension to the cell cycle was observed in mat $A$-homoallelic fusion cells and mitosis was always accompanied by cytokinesis. In mat $A$-homoallelic cultures, many of the binucleate fusion cells split apart without mitosis, regenerating pairs of uninucleate amoebae; in the remaining fusion cells, the nuclei entered mitosis synchronously and spindle fusion sometimes occurred, giving rise to a variety of products. Immunofluorescence microscopy showed that mat $A$-heteroallelic fusion cells possessed two amoebal microtubule organizing centres, and that most zygotes possessed only one; amoebal microtubule organization was lost gradually over several cell cycles. In mat $A$ homoallelic cultures, all the cells retained amoebal microtubule organization.
\end{abstract}

\section{Introduction}

Sexual development in the myxomycete Physarum polycephalum involves the fusion of uninucleate, haploid, vegetative amoebae to form zygotes which give rise to giant, vegetative syncytia known as plasmodia. Two mating-type loci, mat $B$ and $m a t C$, influence the frequency of amoebal fusions, and a third locus, mat $A$, controls the development of fusion cells (Youngman et al., 1979, 1981; Kawano et al., 1987); only cells heteroallelic for matA develop into plasmodia (Youngman et al., 1981). One aim of the present study was to define the role of mat $A$ more precisely by comparing the sequence of cellular events during sexual development in mat $A$-heteroallelic mixtures with the events that occur in mat $A$-homoallelic mixtures.

Mutations associated with the mat $A$ locus give rise to apogamic strains which can form plasmodia asexually;

Abbreviations: DAPI, 4,6-diamidine-2-phenylindole; IMT, intermitotic time; MTOC, microtubule organizing centre. individual amoebae in such strains develop into haploid plasmodia (Anderson et al., 1976; Bailey et al., 1987). A second aim of our study was to compare the sequence and timing of events in sexual development with those already observed in an apogamic strain (Bailey et al., 1987), in order to identify features common to both pathways of development. Time-lapse microcinematography of plasmodium development in the apogamic strain CL (Bailey et al., 1987) showed that either one or both daughter cells from an apparently normal amoebal division could enter an extended cell cycle accompanied by continuing growth. During this cell cycle, ability to undergo the reversible amoeba-flagellate transformation was lost and the cell became irreversibly committed to development. At the end of the extended cell cycle, the large, uninucleate, haploid cell gave rise to a binucleate, haploid cell by mitosis without cytokinesis. This cell developed into a multinucleate plasmodium by rounds of synchronous mitoses unaccompanied by cytokinesis, and by fusion with other binucleate or multinucleate cells. 
In the present study, we used time-lapse microcinematography to examine the timing of cell fusion in relation to the amoebal cell cycle, and to determine whether an extended cell cycle with continuing growth occurred during sexual development. An earlier filming study (Holt \& Huttermann, 1979; Holt et al., 1979) had shown that nuclear fusion in mat $A$-heteroallelic fusion cells occurred in interphase, about $2 \mathrm{~h}$ after amoebal fusion, but that nuclear fusion in $m a t A$-homoallelic fusion cells did not occur until mitosis, which was accompanied by cytokinesis. However, no information could be obtained from these films about the origins or final fates of individual cells because the cultures were filmed only for short periods.

Immunofluorescence microscopy was used to investigate the changes in microtubule organization that follow amoebal fusion in mat $A$-heteroallelic and mat $A$-homoallelic cultures, and to compare these with the extensive changes in microtubule organization that have been observed during apogamic development (Havercroft \& Gull, 1983; Gull et al., 1985; Blindt, 1987).

\section{Methods}

Strains. The amoebal strains used were LU859 (matA2 matB1 matC1; Cooke, 1974), CH508 (matA2 matB3 matC2; Youngman et al., 1979) and LU648 (matAl matBl matCI; Cooke \& Dee, 1975). Stocks were maintained on lawns of Escherichia coli on liver infusion agar at $26^{\circ} \mathrm{C}$ (Bailey et al., 1987). All experiments were done at $22^{\circ} \mathrm{C}$.

Time-lapse microcinematography. Filming was done in cavity slides using the equipment and conditions described by Bailey et al. (1987). Two mixtures of strains were filmed. The mixture CH508 $\times$ LU648 was heteroallelic for matA while the mixture CH508 $\times$ LU859 was homoallelic for $m a t A$; both mixtures were heteroallelic for $m a t B$ and $m a t C$. Encysted amoebae were mixed together and inoculated into slide cultures at a starting density of $20-25$ cells $\mathrm{mm}^{-2}$. The cells had excysted and increased in number to $40-100$ cells $\mathrm{mm}^{-2}$ by the time filming began (18-27 $\mathrm{h}$ after inoculation) giving 35-60 cells within the film frame. Filming was continued for $32-34 \mathrm{~h}$ at one frame per $15 \mathrm{~s}$. Clonal cultures of amoebae were set up using the same initial cell density and were filmed for the same length of time.

Film analysis. The intervals between cellular events were measured using an analysing projector as described by Bailey et al. (1987). In the slide cultures, the cells were flattened between an agar block and a coverslip. Bailey et al. (1987) demonstrated that, within a single slide culture, measurements of cell area could provide a reliable means of investigating cell growth; amoebal area approximately doubled during each cell cycle. In order to measure cell area, the films were projected onto a screen divided into 8800 squares, each corresponding to $7 \cdot 30 \mu \mathrm{m}^{2}$ ( 1 arbitrary unit) in the slide culture. Since the amount of cell flattening varied from slide to slide, all measurements were taken from a single film. In the text, area measurements are given in arbitrary units. It should be noted that the arbitrary unit of area used by Bailey $e t$ al. (1987) was different $\left(4.86 \mu \mathrm{m}^{2}\right)$ because a different magnification was used for the films. Statistical analyses were done using $t$-tests unless stated otherwise; significance levels are given in the text.

Immunofluorescence microscopy.

Media and reagents. Phosphate-buffered saline (PBS). This was prepared by adding $2.56 \mathrm{~g} \mathrm{NaH}_{2} \mathrm{PO}_{4}$ and $22.49 \mathrm{~g} \mathrm{Na}_{2} \mathrm{HPO}_{4}$ to $500 \mathrm{ml}$ water and adjusting the $\mathrm{pH}$ to $7 \cdot 2-7 \cdot 4$; to this was added $87.66 \mathrm{~g} \mathrm{NaCl}$ and the volume was made to 1 litre; this stock solution was diluted 1 in 10 with water before use.

Poly-L-lysine solution. A $50 \mu \mathrm{g} \mathrm{ml}^{-1}$ solution in $10 \mathrm{mM}-\mathrm{Tr}$ is $/ \mathrm{HCl}$ buffer ( $\mathrm{pH} \mathrm{8.0)}$ was stored at $-20^{\circ} \mathrm{C}$. Poly-L-lysine-coated coverslips were prepared by soaking detergent-washed coverslips (Chance no. 1.5 ) in the poly-L-lysine solution for $10 \mathrm{~min}$ at room temperature and then allowing them to dry. The coated coverslips were stored in airtight containers.

DAPI/anti-fade. $p$-Phenylenediamine (100 mg; Sigma) was added to $10 \mathrm{ml} 1 \mathrm{M}-\mathrm{Tris} / \mathrm{HCl}(\mathrm{pH} \mathrm{7.5)}$ and the volume was made up to $100 \mathrm{ml}$ with glycerol. DAPI (4,6-diamidine-2-phenylindole, Sigma; $2.5 \mathrm{mg}$ ) was added to the glycerol solution which was subsequently stored at $-20^{\circ} \mathrm{C}$.

Fixation and staining of cells. Encysted amoebae of two strains were harvested and mixed to give a suspension containing $2 \times 10^{6}$ cells ml$^{-1}$ of each strain. Liver infusion agar plates, containing $3 \mathrm{~mm}$-sodium citrate buffer, $\mathrm{pH} 5 \cdot 0$, were inoculated with $0.1 \mathrm{ml}$ of cell suspension and $0.1 \mathrm{ml}$ of a 1 in 3 dilution of formalin-killed bacteria (Bailey $e t$ al., 1987). This mixture was spread to form a square of side $5 \mathrm{~cm}$ and incubated at $22{ }^{\circ} \mathrm{C}$. At various times after inoculation, the cells were washed off five plates with $2 \mathrm{ml}$ of water per plate, and the suspensions were combined. The cells were spun down and resuspended in water at $5 \times 10^{6} \mathrm{ml}^{-1}$. Drops of suspension $(20 \mu \mathrm{l})$ were placed on poly-L-lysine coated coverslips and the cells were allowed to settle for $40 \mathrm{~min}$ before being fixed by immersion in methanol at $-20^{\circ} \mathrm{C}$ for $10 \mathrm{~s}$. The cells were rehydrated in PBS and $10 \mu \mathrm{l}$ of the first antibody added for $1 \mathrm{~h}$ (anti- $\beta$-tubulin, Amersham; dilution 1:1000 in PBS); this antibody recognizes $\beta$-tubulin in a wide variety of cell types (Blose et al., 1982). After several washes in PBS, $10 \mu$ l of the second antibody was added for I h (fluorescein-isothiocyanate-conjugated goat-antimouse IgG, Tago Inc., USA; dilution 1:50 in PBS). The coverslips were then re-washed in PBS and mounted onto glass microscope slides using the glycerol/DAPI/anti-fade mix. Slides were examined using a Zeiss Axiophot microscope fitied with a $\times 100$ Plan-neofluar objective. Amoebal strains grown alone and treated identically were used as controls.

A different preparation method was required for flagellates because flagella are quickly resorbed when the cells are placed on a surface. Cells were removed from culture plates as described above and resuspended at $5 \times 10^{6}$ cells $\mathrm{ml}^{-1}$ in water. To induce flagellate formation, $2 \mathrm{ml}$ of suspension was shaken at 200 strokes $\mathrm{min}^{-1}$ on a reciprocating shaker for $3 \mathrm{~h}$ at $26^{\circ} \mathrm{C}$. The cells were fixed in suspension by adding $0.1 \mathrm{vol}$ formaldehyde ( $38 \%, \mathrm{w} / \mathrm{v}$, stock solution). After $1 \mathrm{~h}$, the cells were thoroughly washed in PBS, placed in methanol at $-20{ }^{\circ} \mathrm{C}$ for $10 \mathrm{~s}$, and finally rinsed in acetone for $5 \mathrm{~min}$ before being thoroughly washed in PBS. The cells were resuspended in PBS at 1-5 $\times 10^{6}$ cells $\mathrm{ml}^{-1}$. Drops of suspension were placed on poly-L-lysine coated coverslips and allowed to dry; the cells were then stained as described above.

\section{Results}

Time-lapse cinematographic analysis of events preceding amoebal fusion

Three films were made of mixed cultures inoculated with a pair of amoebal strains carrying different mat $A$ alleles $(\mathrm{CH} 508 \times$ LU648) and two films of mixed cultures in which both strains carried the same matA allele (CH508 $\times$ LU859). Fusions between amoebae were observed during the course of all five films. Sexual 
Table 1. Timing of events

Times are given as the mean $(h) \pm S D$; the number of observations, $n$, is given in parentheses.

\begin{tabular}{|c|c|c|c|c|c|c|}
\hline Strains & $\begin{array}{c}\text { (a) } \\
\text { Amoebal } \\
\text { IMT }^{*}\end{array}$ & $\begin{array}{c}(b) \\
\text { Mitosis }\left(\mathbf{M}_{1}\right) \\
\text { to cell } \\
\text { fusion } \dagger\end{array}$ & $\begin{array}{c}(c) \\
\text { Cell fusion } \\
\text { to } \\
\text { mitosis }\left(M_{2}\right)\end{array}$ & $\begin{array}{l}\quad(d) \\
\text { Cell fusion } \\
\text { to split } \ddagger\end{array}$ & $\begin{array}{c}\text { (e) } \\
\mathbf{M}_{1} \text { to } \mathbf{M}_{2}\end{array}$ & $\begin{array}{c}(f) \\
\text { Binucleate } \\
\text { to } \\
\text { quadrinucleate }\end{array}$ \\
\hline $\begin{array}{l}\text { CH508 } \times \text { LU648 } \\
\text { (Heteroallelic } \\
\text { for matA) }\end{array}$ & $\begin{array}{c}9 \cdot 13 \pm 1 \cdot 46 \\
(69)\end{array}$ & $\begin{array}{c}3 \cdot 46 \pm 1 \cdot 77 \\
(98)\end{array}$ & $\begin{array}{c}16.90 \pm 1.44 \\
(26)\end{array}$ & & $\begin{array}{c}20.58 \pm 1.73 \\
(37)\end{array}$ & $\begin{array}{c}6 \cdot 13 \pm 0 \cdot 62 \\
(12)\end{array}$ \\
\hline $\begin{array}{l}\text { CH508 } \times \text { LU859 } \\
\text { (Homoallelic } \\
\text { for matA) }\end{array}$ & $\begin{array}{c}10.06 \pm 1.44 \\
(45)\end{array}$ & $\begin{array}{c}\text { (1) } 3 \cdot 30 \pm 2 \cdot 21 \\
(72) \\
\text { (2) } 3 \cdot 94 \pm 2 \cdot 46 \\
(19) \\
\text { (3) } 3 \cdot 12 \pm 2 \cdot 11 \\
(48)\end{array}$ & $\begin{array}{l}4 \cdot 89 \pm 2 \cdot 00 \\
(14)\end{array}$ & $\begin{array}{c}2 \cdot 38 \pm 1 \cdot 23 \\
(31)\end{array}$ & $\begin{array}{c}9 \cdot 35 \pm 2 \cdot 32 \\
(20) \\
8 \cdot 15 \pm 1 \cdot 15 \\
(12)\end{array}$ & \\
\hline
\end{tabular}

* Amoebal IMTs for clonal cultures were: LU648, 10.20 \pm 2.02 (76); LU859, 10.34 \pm 1.63 (29); CH508, $10 \cdot 76 \pm 1.52(36)$.

$\dagger$ (1) All cells; (2) fusions where mitosis occurred in the fusion cell; (3) fusion cells in which cell fusion was followed by splitting into two uninucleates.

$\ddagger$ Time from cell fusion to split - see text.

development occurred in the mat $A$-heteroallelic cultures and by the end of each film the field of view was occupied by large plasmodia. In the films of mat $A$-homoallelic cultures, plasmodium development did not occur.

Amoebal intermitotic times. The intermitotic time (IMT) was defined as the time between nucleolar disappearance in successive mitoses. The amoebal IMTs were compared for the three films showing sexual development; analysis of variance showed no significant differences between the films $(F=0.51 ; P>0.05)$ and the data were therefore pooled for further analysis (Table $1 a$ ). The amoebal IMTs measured from the two films of mat $A$-homoallelic cultures were also not significantly different $(P>0.05)$ and these data were pooled (Table $1 a$ ). The distribution of amoebal IMTs from each film appeared unimodal, suggesting that the two strains in each mixture did not show characteristically different IMTs. This conclusion was supported by the analysis of films of each amoebal strain cultured alone under the same conditions used for the mixed cultures; no significant differences were found between the IMTs in these clonal cultures $(P>0.05$; Table $1 a)$. There was, however, a significant difference $(P<0.001)$ between amoebal IMTs in mat $A$-heteroallelic cultures and the amoebal IMTs for all other cultures.

Origins of fusing cells. An example of a pedigree traced from a film of sexual development is shown in Fig. 1. Out of 68 amoebal fusions observed in the films of sexual development, 66 involved pairs of uninucleate amoebae and two were multiple fusions, each of which involved three amoebae. Most of the amoebae participating in fusions $(101 / 138)$ could be traced back to a previous amoebal division, and from 45 of these divisions it was

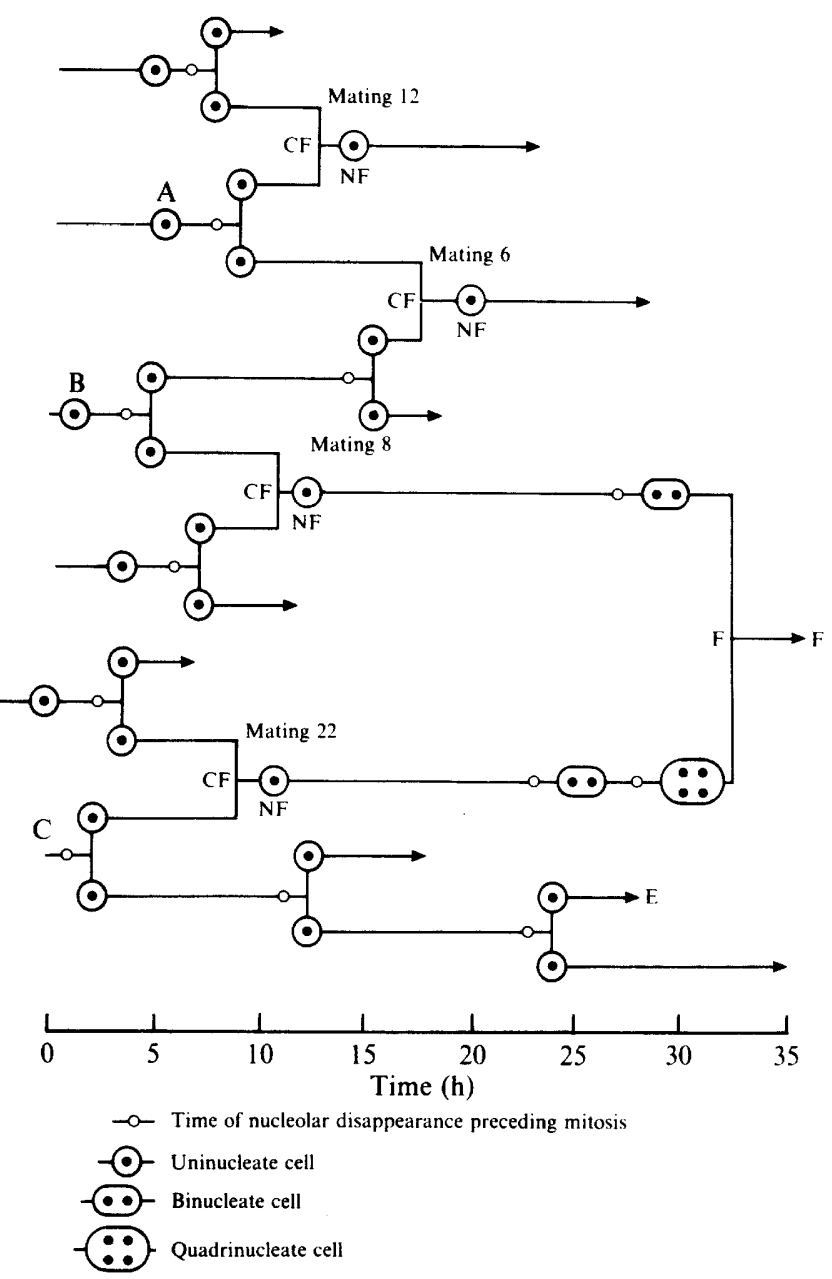

Fig. 1. Representative cell pedigree from a matA-heteroallelic culture. $C F$, cell fusion; NF, nuclear fusion; $F$, fusion of multinucleate cells; $E$, amoeba ingested by plasmodium. $\rightarrow$, Cell left field. A, B, C, see text. Filming began at $0 \mathrm{~h}$. 
(a)

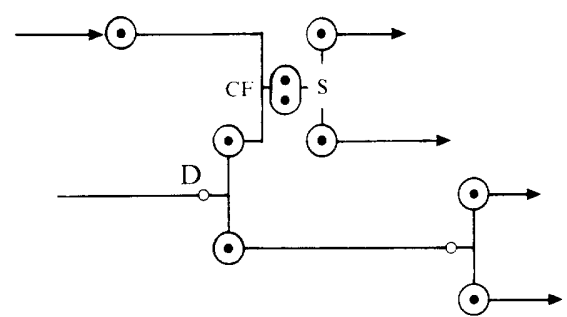

(b)

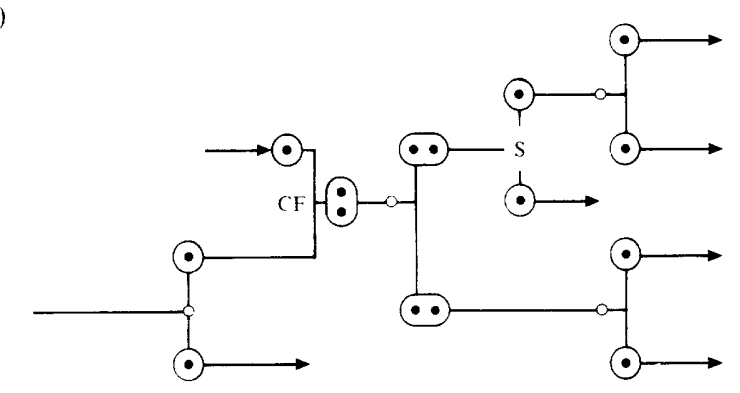

(c)

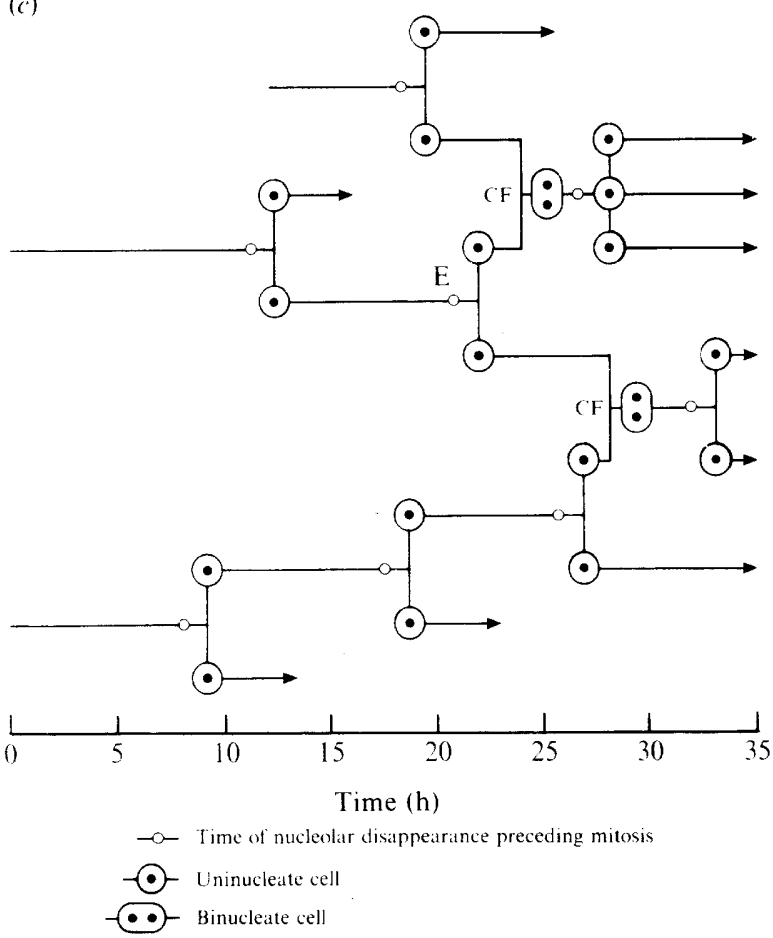

Fig. 2. Three representative cell pedigrees $(a, b$ and $c$ ) from a mat $A$ homoallelic culture showing examples of the different fates of binucleate fusion cells. CF, cell fusion; $\mathrm{S}$, cell splits apart. $\rightarrow$, Cell left field. D, E, see text. Filming began at $0 \mathrm{~h}$.

possible to determine the fates of both daughter cells. There were 21 divisions from which both daughter cells mated (e.g. daughters of cell A in Fig. 1) and 24 divisions from which one daughter mated and the other completed an apparently normal amoebal cell cycle (e.g. daughters of cell B in Fig. 1). The mean IMT of the daughter cells that completed an apparently normal amoebal cell cycle was $8.92 \pm 1.60 \mathrm{~h}(n=24)$, not significantly different from the mean for all amoebal cell cycles $(P>0.05$; Table $1 a$ ). In 24 cases it was possible to measure the length of the cell cycle preceding the one in which fusion occurred; the mean length of this cycle $(8.72 \pm 1.18 \mathrm{~h}$, $n=24$ ) was not significantly different from the mean for all amoebal cell cycles $(P>0.05$; Table $1 a)$.

Fig. 2 shows examples of pedigrees traced from the two films of matA-homoallelic cultures. The events preceding amoebal fusion in these cultures were very similar to those seen in the mat $A$-heteroallelic cultures. Forty-nine fusions were observed, of which two were multiple fusions involving three amoebae. Seventy-two of the amoebae that were seen to fuse were traced back to their origin at the previous amoebal division. Among 24 divisions from which the fates of both daughter cells could be determined, there were 17 divisions from which both daughter cells underwent cell fusion (e.g. daughters of cell E in Fig. 2) and seven divisions from which one daughter cell divided and the other fused (e.g. daughters of cell D in Fig. 2). The mean IMT of daughter cells that completed an apparently normal amoebal cell cycle $(9.85 \pm 1.48 \mathrm{~h}, n=7)$ was not significantly different from the mean for all amoebal cell cycles $(P>0 \cdot 05$; Table $1 a)$. The mean length of the cell cycle preceding the one in which cell fusion occurred $(10.02 \pm 1.45 \mathrm{~h}, n=23)$ also showed no significant difference from the mean for all amoebal cell cycles $(P>0.05$; Table $1 a)$.

Age of amoebae at cell fusion. The films were analysed to determine whether the fusion of amoebae occurred at a constant time after mitosis. Fig. 3(a) shows the time from the start of mitosis (defined by nucleolar disappearance in prophase) to cell fusion in the mat $A$-heteroallelic cultures; Fig. 3(b) shows the same information for the mat $A$-homoallelic cultures. No fusions occurred for about 20 min following the start of mitosis (M in Fig. $3 a$, $b)$; this period corresponds to the time taken to undergo mitosis and cytokinesis ( $\mathrm{D}$ in Fig. $3 a, b$ ). Thereafter, amoebal fusions were distributed throughout a period roughly equal to the mean length of an amoebal cell cycle (marked as IMT on Fig. $3 a, b$; Table $1 a, b$ ). The data were further analysed to determine whether there was a consistent relationship between the ages of a fusing pair (Fig. 4). For example, if an amoeba could fuse only with another of similar age, the points in Fig. 4 would lie along line A. Alternatively, if the combined age of each pair of amoebae was constant, the points in Fig. 4 would lie along line B. The distribution of points in Fig. 4 suggests that fusions between amoebae occur irrespective of cell age.

Multiple amoebal fusions. In three of the four multiple fusions observed during filming, the origins of the fusing amoebae could be traced. In one fusion, in a culture heteroallelic for matA, a cell $4.9 \mathrm{~h}$ old fused simul- 

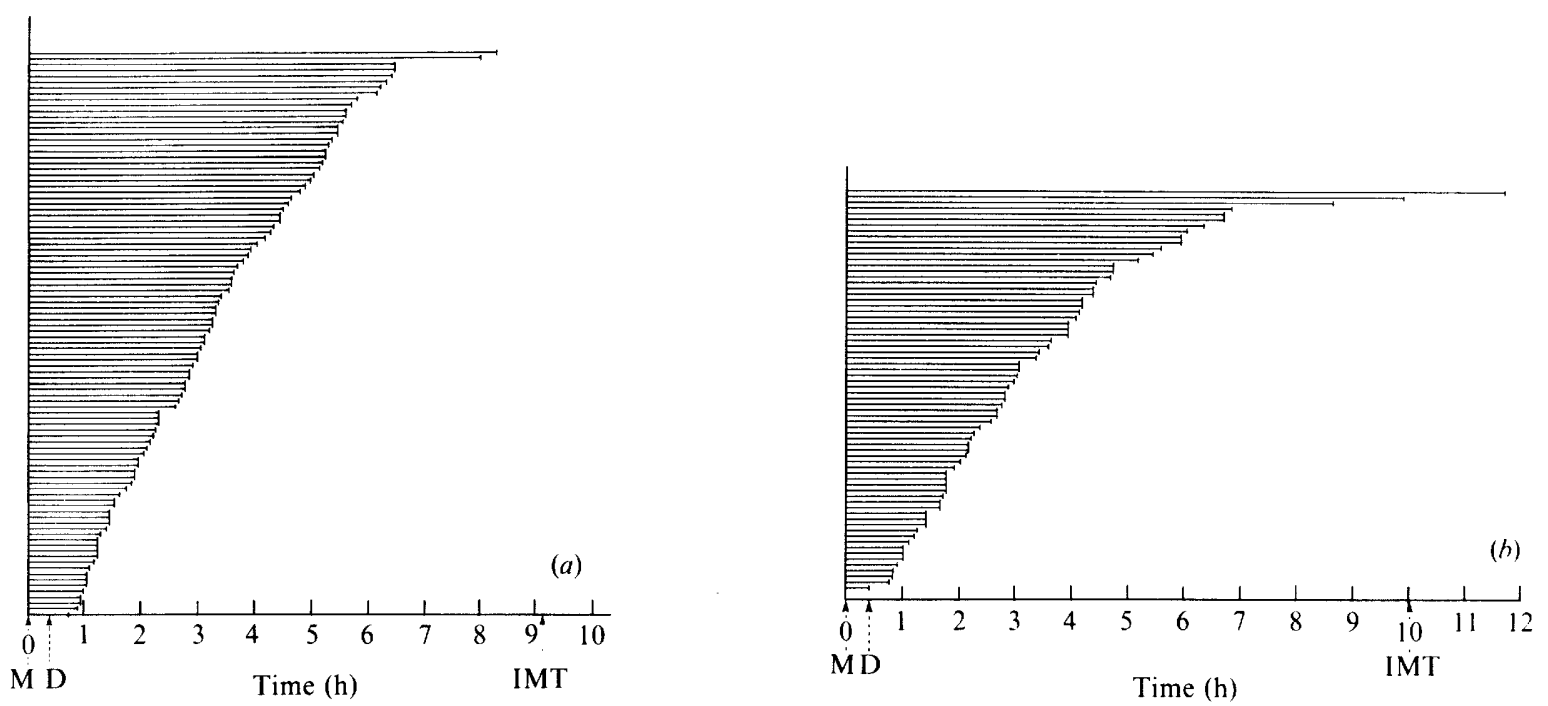

Fig. 3. Ages of amoebae at cell fusion. Each bar represents the age of one amoeba at the time of cell fusion, measured from nucleolar disappearance at mitosis $(M)$. The interval between $M$ and $D$ represents the mean time between the start of mitosis and the completion of cytokinesis. IMT represents the mean amoebal IMT. (a) mat $A$-heteroallelic cells. (b) mat $A$-homoallelic cells; this Figure represents the data on first fusions only (see text).

taneously with a pair of sister cells $1.9 \mathrm{~h}$ old. In another fusion, in a $m a t A$-homoallelic culture, a cell $4.7 \mathrm{~h}$ old fused simultaneously with sister cells $1.7 \mathrm{~h}$ old. The final fusion in which the origin of the fusing cells could be traced did not involve the fusion of sister cells; this fusion, also in a mat $A$-homoallelic culture, began with the fusion of two cells 4.0 and $4.7 \mathrm{~h}$ old and was followed 2 min later by fusion with a third cell $4.3 \mathrm{~h}$ old.

Time-lapse cinematographic analysis of the events following amoebal fusion

In $m a t A$-heteroallelic cultures, nuclear fusion occurred in interphase about $2 \mathrm{~h}$ after cell fusion $(2.05 \pm 0.67 \mathrm{~h}$, $n=59$ ). In mat $A$-homoallelic cultures, no interphase nuclear fusions were observed. Among the 45 mat Ahomoallelic fusion cells followed, two different fates were observed: 14 remained binucleate until both nuclei entered mitosis synchronously some hours later (Fig. $2 b$, $c)$; the remaining 31 fusion cells split without mitosis to regenerate pairs of uninucleate cells (Fig. 2a). Of the 62 uninucleate cells formed by cell splitting, seven were later seen to fuse with different partners. In mat $A$-homoallelic cultures there was no consistent relationship between the ages of amoebae at cell fusion and the fates of the binucleate fusion cells (Fig. 4).

The films showed that sexual development in matAheteroallelic cultures included an extended cell cycle preceding binucleate plasmodium formation. The length of this cell cycle was calculated by adding the mean age of the pair of fusing amoebae to the time between cell fusion and the following mitosis at which the zygote

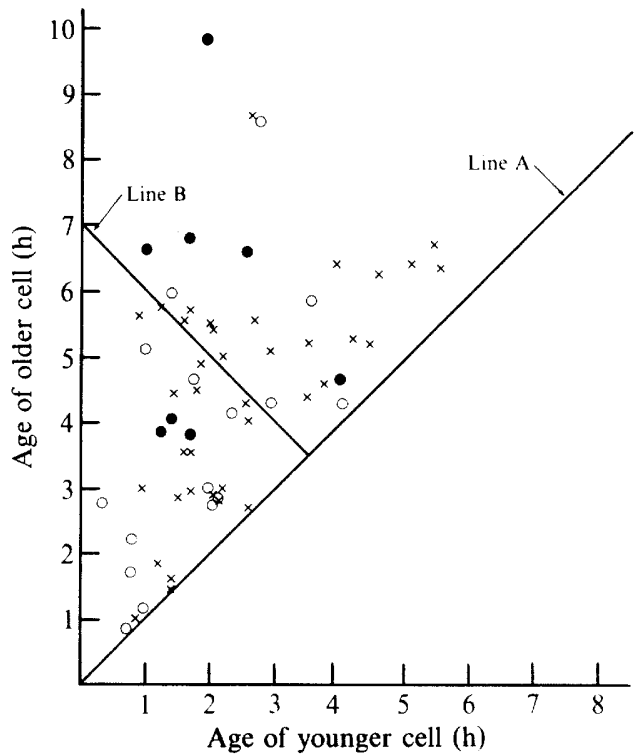

Fig. 4. Ages of pairs of mating amoebae. Line A, expected distribution if only amoebae of similar age are able to fuse; line B, expected distribution if the combined age for each pair of mating amoebae was similar. See text for further explanation. $\times$, Fusions in mat $A$ heteroallelic cultures; , fusions in mat $A$-homoallelic cultures where fusion ends with mitosis; $O$, fusions in mat $A$-homoallelic cultures where fusion ends in cell splitting.

became binucleate (Table $1 e$ ). The extended cell cycle was approximately 2.3 times the length of the mean amoebal cell cycle; the following cell cycle, leading to the formation of a quadrinucleate cell, was shorter than the mean amoebal cell cycle (Table $1 f$ ).

In mat $A$-homoallelic cultures, no extended cell cycle was observed; for the 14 fusion cells that remained 
binucleate until mitosis, the mean time between the mitosis preceding cell fusion and the synchronous mitoses in the fusion cell was not significantly different from the mean amoebal IMT $(P>0.05$; Table $1 a, e)$. For the 31 fusion cells that split to yield two uninucleates, the mean time between the mitoses preceding and following amoebal fusion was significantly shorter than the mean length of an amoebal cell cycle $(P<0 \cdot 001$; Table $1 a, e)$.

When mat $A$-homoallelic fusion cells entered mitosis, both nuclei proceeded synchronously. The nucleolus moved to the side of the nucleus before disappearing and shortly afterwards the prophase nuclei vanished. This sequence of events was different from that observed in zygotes, in which the nucleus remained visible throughout mitosis; metaphase plate formation and chromosome separation were clearly visible inside the zygotic nucleus. In seven mat $A$-homoallelic fusion cells, nuclear fusion occurred during prophase and two uninucleate, presumably diploid daughter cells were formed after cytokinesis [Table 2, class (a); Fig. 2c]; two daughter cells, from one such division, could be followed until the next mitosis, at which time both divided into three. The mean IMT for these putative diploid amoebae $(8.95 \pm 0.27 \mathrm{~h})$ was significantly shorter than the mean IMT for haploid amoebae $(P<0.001)$. In three fusion cells undergoing mitosis, nuclear fusion was not observed; each cell gave rise to two binucleate daughters [Table 2, class (b); Fig. $2 b$ ]. The binucleate daughter cells showed the same fates as newly formed fusion cells, either splitting into two uninucleates (three cases) or entering mitosis as a binucleate cell (one case; Fig. $2 b$ ). Two other mat $A$-homoallelic fusion cells observed in mitosis divided to give three daughters [Table 2, classes $(c)$ and (d); Fig. 2c].

Multiple amoebal fusions. In matA-heteroallelic cultures, it was possible to determine the fates of the three nuclei in each of the fusion cells formed by multiple amoebal fusions. Two of the nuclei in each cell fused together about $2 \mathrm{~h}$ after cell fusion, followed by fusion of the third nucleus $30-40 \mathrm{~min}$ later. The resulting zygotes became binucleate $16-17 \mathrm{~h}$ after cell fusion and one was observed to become quadrinucleate $5 \cdot 2 \mathrm{~h}$ after becoming

Table 2. Products of mitosis in binucleate fusion cells homoallelic for mat $A$

\begin{tabular}{lcccc}
\hline \hline & $\begin{array}{c}\text { No. of cells } \\
\text { undergoing } \\
\text { Class }\end{array}$ & \multicolumn{2}{c}{ Daughter cells } & \\
\cline { 3 - 4 } & mitosis & uninucleate & binucleate & $\begin{array}{c}\text { Daughter } \\
\text { nuclei }\end{array}$ \\
\hline$(a)$ & 7 & 2 & 0 & 2 \\
$(b)$ & 3 & 0 & 2 & 4 \\
$(c)$ & 1 & 2 & 1 & 4 \\
$(d)$ & 1 & 3 & 0 & 3 \\
\hline \hline
\end{tabular}
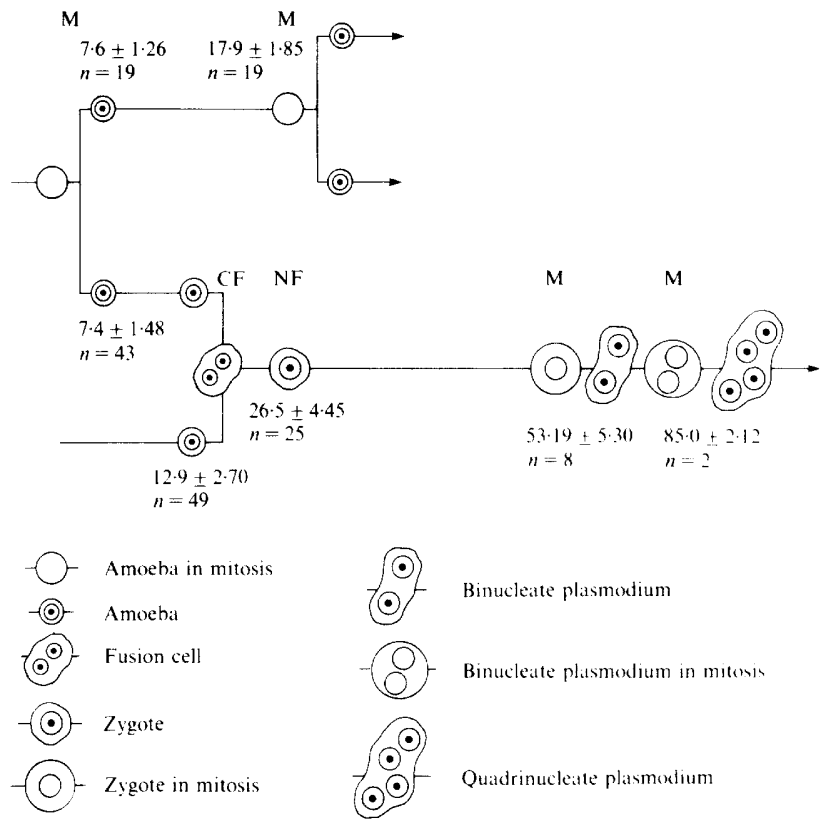

Fig. 5. Areas of cells during sexual development. Mean area is given in arbitrary units $( \pm S D)$ for a sample of cells at each stage indicated on the pedigree. All measurements are taken from one film; 1 arbitrary unit $=7.30 \mu \mathrm{m}^{2}$ (see Methods), $n=$ number of cells measured. $M$, mitosis; CF, cell fusion; NF, nuclear fusion.

binucleate. Both cells eventually fused with larger plasmodia and the subsequent fates of their nuclei could not be determined.

In both the multiple fusions involving amoebae homoallelic for mat $A$, the resulting trinucleate cells split to form a binucleate and a uninucleate. One binucleate cell subsequently separated into two uninucleates whose final fate could not be determined. The other binucleate cell entered mitosis and gave rise to two binucleate daughters whose subsequent fates could not be determined.

\section{Cell growth and nuclear area}

During amoebal cell cycles, cells approximately doubled in area (e.g. Fig. 5). In $m a t A$-heteroallelic cultures, amoebae that participated in mating were not significantly different in area, at birth, from amoebae that divided to yield daughter cells $(P>0.05 ;$ Fig. 5$)$. At the time of mating, amoebal areas ranged from 7.5 to 21 arbitrary units; this large variation in area was consistent with the variation in cell age at fusion (Fig. 3a). During the extended cell cycle, zygotes continued to grow until, at the first plasmodial mitosis, they were approximately 3 times the area of amoebae in mitosis (Fig. 5). In contrast, mat $A$-homoallelic fusion cells in mitosis were approximately 1.5 times the area of amoebae in mitosis. Cell area failed to double in the short cell cycle that ended with the 

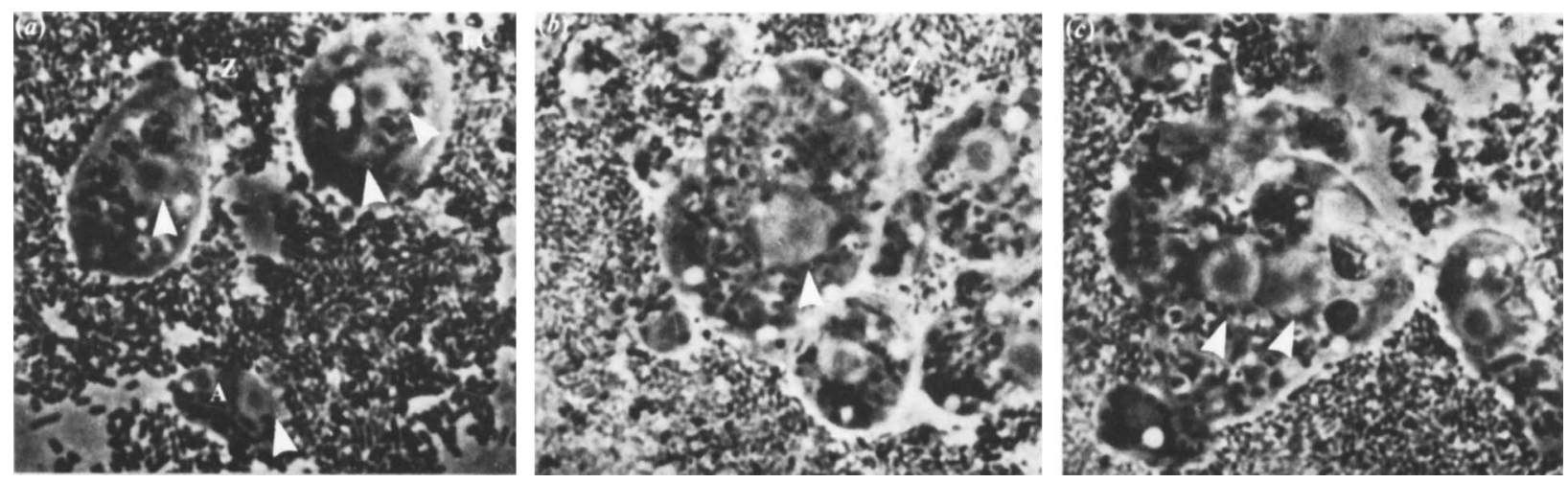

Fig. 6. Changes in cell and nuclear area during sexual development. Nuclei. Bar, $10 \mu \mathrm{m}$. (a) A, haploid amoeba; FC, fusion cell with two small haploid nuclei; $Z$, diploid zygote just after nuclear fusion. (b) $Z$, zygote entering mitosis at the end of the extended cell cycle; note large size of cell and nucleus relative to those in $(a) .(c)$ Binucleate plasmodium; the two diploid nuclei are approximately the same size as the zygote nucleus in $(a)$.

formation of a quadrinucleate plasmodium, increasing by a factor of only 1.6 (Fig. 5).

Increase in plasmodial size occurred both by growth of individual plasmodia and by fusions between plasmodia. Many fusions were observed between plasmodia with two or more nuclei, but no fusions were seen between uninucleate zygotes. Two zygotes fused with multinucleate plasmodia; both zygotes were undergoing mitosis at the time of fusion and completed mitosis after fusion.

Following nuclear fusion in $m a t A$-heteroallelic fusion cells, nuclear area increased during the remainder of the extended cell cycle; at mitosis, nuclear area was substantially greater than twice the nuclear area of a haploid amoeba entering mitosis (compare nuclear areas in Fig. $6 a, b, c)$. Nevertheless, in quadrinucleate cells the area of each diploid nucleus was approximately twice the area of a haploid amoebal nucleus. In mat $A$-homoallelic cultures, all the observed changes in nuclear area were consistent with the changes in ploidy assumed to have occurred at mitosis.

\section{Microtubule organization during plasmodium development}

Amoebae possess a complex array of cytoplasmic microtubules nucleated by a microtubule organizing centre (MTOC) which is closely associated with a pair of centrioles and linked to the nucleus. During amoebal mitosis, the MTOC and centrioles duplicate, divide, and migrate to form the two poles of the mitotic spindle. Plasmodia possess no centrioles, and microtubules are present only in the mitotic spindle which, unlike the amoebal spindle, is formed inside an intact nuclear membrane (Howard, 1932; Tanaka, 1973; Havercroft \& Gull, 1983).

The changes in microtubule organization during plasmodium development were studied using immuno-
Table 3. Numbers of cells with no, one or two MTOCs at different stages of development

\begin{tabular}{|c|c|c|c|c|}
\hline \multirow{2}{*}{$\begin{array}{c}\text { Stage of } \\
\text { development }\end{array}$} & \multicolumn{3}{|c|}{ Number of interphase cells with: } & \multirow{2}{*}{$\begin{array}{l}\text { Total } \\
\text { scored }\end{array}$} \\
\hline & No MTOC & 1 MTOC & 2 MTOCs & \\
\hline \multirow{3}{*}{$\begin{array}{l}\text { Fusion cell } \\
\text { Zygote } \\
\text { Binucleate } \\
\text { plasmodium }\end{array}$} & $4(16 \%)$ & $8(32 \%)$ & $13(52 \%)$ & 25 \\
\hline & $110(33 \%)$ & $212(64 \%)$ & $11(3 \%)$ & 333 \\
\hline & $26(58 \%)$ & $10(22 \%)$ & $9(20 \%)$ & 45 \\
\hline
\end{tabular}

fluorescence microscopy of cells stained with an anti- $\beta$ tubulin monoclonal antibody. The nuclei were stained with the DNA-specific fluorochrome DAPI. Counts were made of the number of MTOCs present in a sample of interphase fusion cells, zygotes and binucleate plasmodia (Table 3). Binucleate fusion cells were recognized by the presence of two nuclei similar in size to those of vegetative amoebae (Fig. 6a); the majority of these cells contained two MTOCs (Fig. $7 a, b$ ) although some possessed none or one. Zygotes were recognized as large cells containing a single large nucleus (Fig. $6 b$ ); only $3 \%$ of these possessed two MTOCs, the majority possessing one (Fig. $7 c, d$ ). Binucleate plasmodia were identified by the presence of two large nuclei within a large cell (Fig. 6c); most of these did not possess a MTOC (Table 3). Microtubules were present in all binucleate plasmodia, but in cells lacking a MTOC, the microtubules did not radiate from a single focus. Plasmodia with more than two nuclei were excluded from consideration because they could have been the result of fusion between smaller plasmodia.

In amoebae stained with the anti- $\beta$-tubulin antibody, a pair of small dots was seen closely associated with the MTOC; similar structures were present at the spindle poles of mitotic amoebae, suggesting that they were the centrioles. A stained cell population was used to 

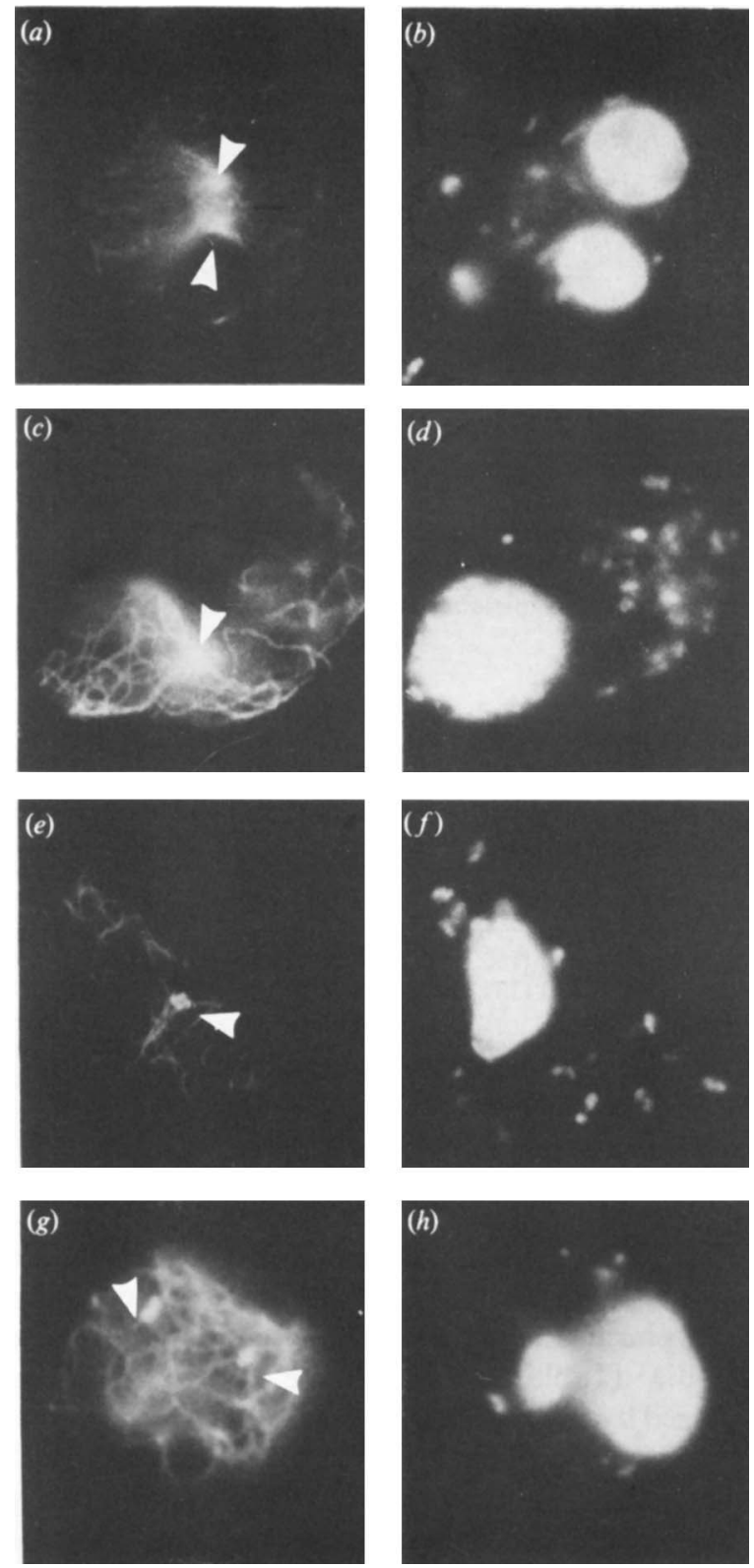

Fig. 7. Interphase cells from a mat $A$-heteroallelic culture, doublestrained with $\beta$-tubulin antibody to show microtubules $(a, c, e$ and $g$ ) and with DAPI to show DNA $(b, d, f$ and $h)$. The dots in the cytoplasm in $(b),(d),(f)$ and $(h)$ are a mixture of mitochondria and ingested bacteria. Bar, $1 \mu \mathrm{m}$. $(a, b)$ Fusion cell with two MTOCs $(>)$ and two small nuclei. $(c, d)$ Zygote with one MTOC () and a single large nucleus. $(e, f)$ Zygote with two pairs of centrioles in a cluster $(-)$ and a single large nucleus. $(g, h)$ Zygote with two separate pairs of centrioles ( ) and a single large nucleus.

determine the number of pairs of centrioles present in cells at different stages of development. Out of 98 zygotes in which centrioles could be scored, 77 possessed two pairs of centrioles; these were either present as a group of four ( 62 cells; Fig. $7 e, f)$ or as two separate pairs ( 15 cells; Fig. $7 g, h)$. The remaining 21 zygotes each possessed only
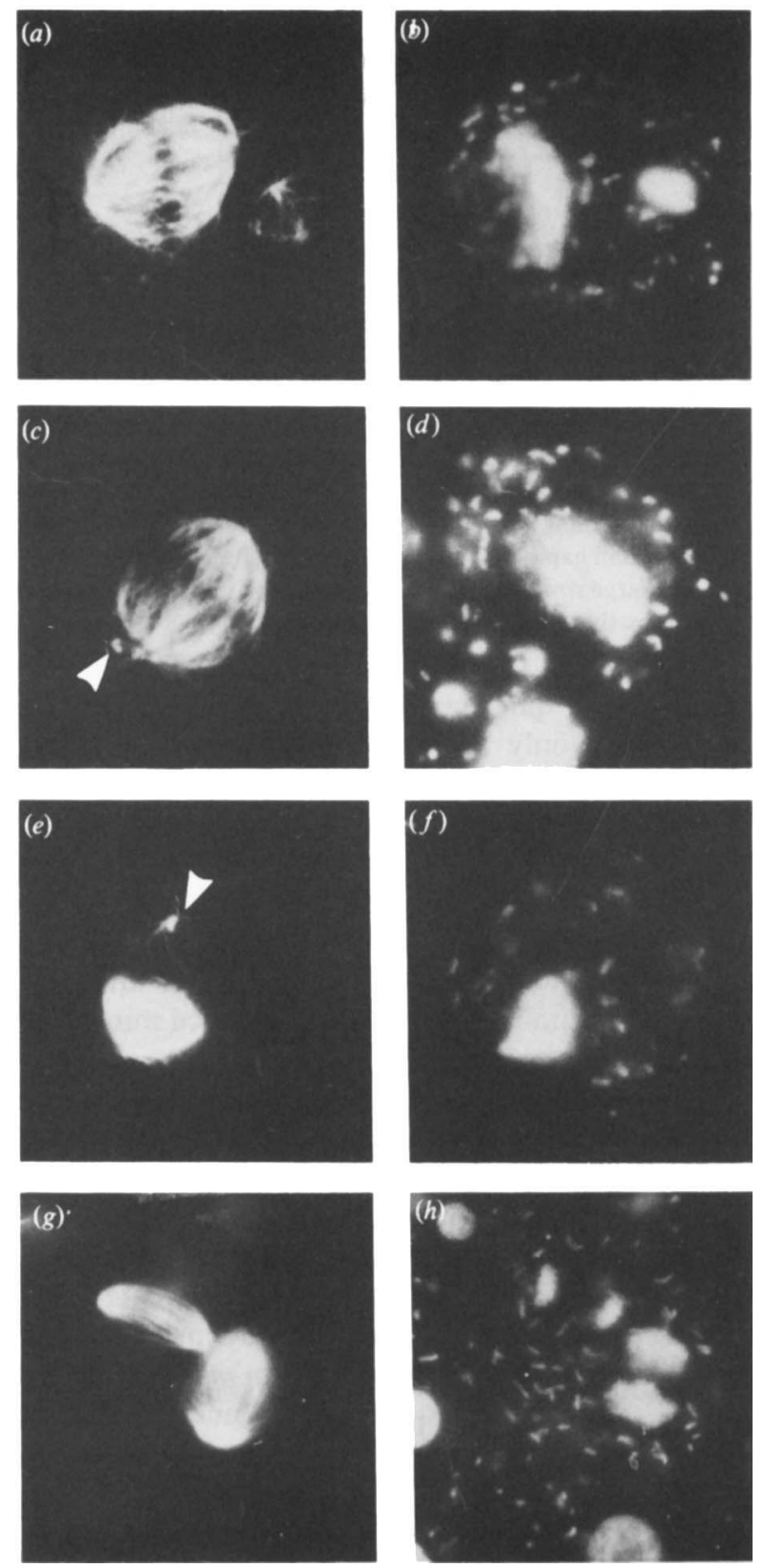

Fig. 8. Mitotic cells from a mat $A$-heteroallelic culture, double-stained with $\beta$-tubulin antibody to show microtubules $(a, c, e$ and $g)$ and with DAPI to show DNA $(b, d, f$ and $h)$. The dots in the cytoplasm in $(b),(d)$, $(f)$ and $(h)$ are a mixture of mitochondria and ingested bacteria. Bar, $1 \mu \mathrm{m} .(a, b)$ Zygote in mitosis with no extranuclear MTOC; the small object to the right of the mitotic nucleus is the remains of an ingested amoeba with nucleus and microtubules still visible. $(c, d)$ Zygote in mitosis with extranuclear MTOC or centrioles present at one pole of the spindle $(-) .(e, f)$ Zygote in mitosis with an extranuclear MTOC or centrioles $(-)$; no ingested amoebae are present. $(g, h)$ Binucleate plasmodium in mitosis; no extranuclear MTOC is present.

one pair of centrioles. Centrioles could not be observed in 71 of the zygotes examined.

Of zygotes in mitosis, $18(35 \%)$ possessed an extranuclear structure labelled by the anti- $\beta$-tubulin antibody; 
it was not possible to determine whether this structure was a MTOC or one or more pairs of centrioles. This extranuclear structure lay either on the side of the cell opposite the dividing nucleus (Fig. 8e,f) or at one pole of the spindle (Fig. $8 c, d$ ) and thus was evidently not nucleating the spindle. No extranuclear MTOC or centrioles were visible in the remaining $34(65 \%)$ zygotes examined (Fig. $8 a, b$ ).

Of 29 binucleate plasmodia, ten possessed centrioles; three had one pair, six had two pairs and one had four pairs. No binucleate plasmodia in mitosis were observed to possess extranuclear centrioles or a MTOC (Fig. $8 g, h)$.

\section{Microtubule organization during mitosis in cultures homoallelic for matA}

Filming analysis indicated that there were several possible outcomes for mitosis in a binucleate cell homoallelic for matA (Fig. 2, Table 2). Immunofluorescence microscopy of five binucleate fusion cells showed that the mitotic spindles lay in various orientations. In two cells the spindles lay end-to-end and in one of these only three spindle poles were observed (Fig. $9 a, b$ ). Since a cleavage furrow usually forms at the equator of a spindle when cytokinesis follows mitosis (Rappaport, 1971), the mitosis shown in Fig. $9(a, b)$ would be expected to produce three daughter cells [Fig. $2 c$; Table 2 , classes $(c)$ and $(d)]$, of which one would contain either two haploid nuclei or one diploid nucleus. Two binucleate cells were observed in which the mitotic spindles were parallel (Fig. 9c,d); cytokinesis in such cells would be expected to produce two daughter cells, which might be diploid uninucleate or haploid binucleate [Fig. $2 b, c$; Table 2 , classes $(a)$ and $(b)$ ]. In the fifth cell the spindles were approximately perpendicular.

The mitotic spindle was also examined in putative diploid amoebae, of which 37 contained bipolar spindles and 12 contained tripolar spindles (Fig. 9e, $f$ ). The presence of tripolar spindles was consistent with our conclusion from filming analysis that diploid amoebae could divide to give three daughter cells.

A count of the number of MTOCs in interphase cells homoallelic for matA showed that $46(67 \%)$ binucleate, haploid cells and nine $(4.3 \%)$ putative diploid amoebae possessed two MTOCs.

\section{Flagellate formation}

In moist conditions, amoebae rapidly transform into flagellates in which the centrioles form the basal bodies for the one long (anterior) and one short (posterior) flagella; the posterior flagellum is usually pressed against the side of the cell and is difficult to observe. To
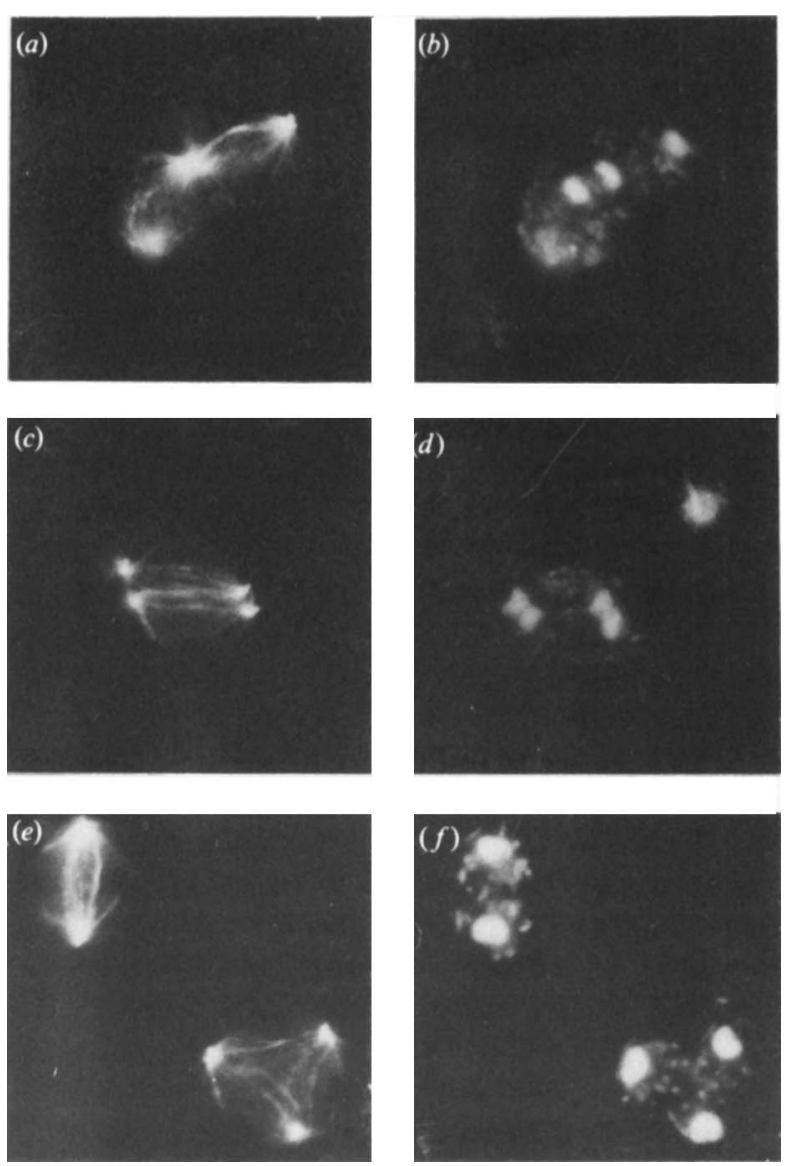

Fig. 9. Mitotic cells from matA-homoallelic cultures double-stained with $\beta$-tubulin antibody to show microtubules $(a, c$ and $e$ ) and with DAPI to show DNA $(b, d$ and $f)$. The dots in the cytoplasm in $(b),(d)$ and $(f)$ are a mixture of mitochondria and ingested bacteria. Bar, $1 \mu \mathrm{m}$. $(a, b)$ Binucleate cell in synchronous mitosis; the spindles have fused at one pole. $(c, d)$ Binucleate cell in synchronous mitosis; four sets of chromosomes and four spindle poles are visible. $(e, f)$ Two uninucleate cells in mitosis; one spindle is bipolar while the other is tripolar.

determine the stage of sexual development at which the ability to undergo the amoeba-flagellate transformation was lost, flagellate formation was induced in a mat $A$ heteroallelic population. A sample of each cell type was scored for the presence or absence of the long flagellum. Of the 500 amoebae scored, $87 \%$ were flagellates and all of these possessed one long flagellum (Fig. 10a,b). All five fusion cells observed were flagellates; four possessed one long flagellum and the other possessed two. Only 46 flagellates were observed amongst 420 zygotes; 41 possessed one long flagellum (Fig. $10 c, d$ ) and five possessed two. No flagella were observed on the 50 binucleate and multinucleate plasmodia scored. In a mat $A$-homoallelic culture only $4 \%$ of cells failed to transform into flagellates; $6.2 \%$ of the population had two long flagella and the remainder had one. 

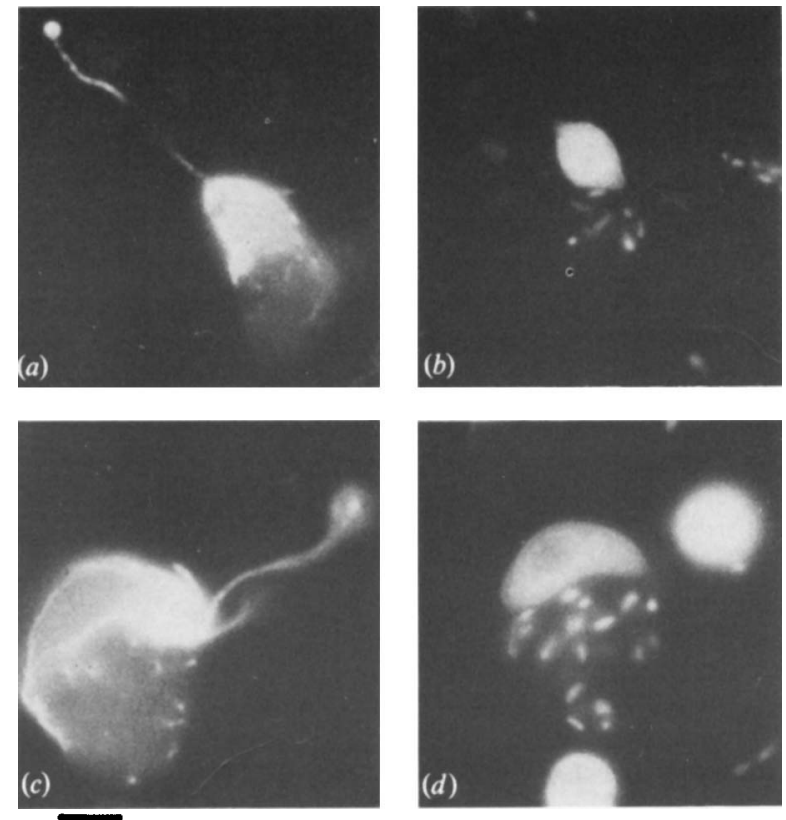

Fig. 10. Flagellates from a mat $A$-heteroallelic culture, double-stained with $\beta$-tubulin antibody to show microtubules ( $a$ and $c$ ) and with DAPI to show DNA ( $b$ and $d$ ). The dots in the cytoplasm in $(b)$ and $(d)$ are a mixture of mitochondria and ingested bacteria. Bar, $1 \mu \mathrm{m} .(a, b)$ Flagellate presumably derived from an amoeba. $(c, d)$ Flagellate presumably derived from a zygote.

\section{Discussion}

Our filming analysis has provided support for the suggestion that matA has no effect on cell fusion (Youngman et al., 1981). Amoebal fusions occurred frequently in cultures either heteroallelic or homoallelic for $m a t A$. In both types of culture, cell age at the time of cell fusion varied widely between a minimum of about $20 \mathrm{~min}$ and a maximum approximately equal to an amoebal cell cycle (Fig. 3); the age distributions were very similar in the two types of culture. In both mat $A$ heteroallelic and mat $A$-homoallelic cultures, the majority of amoebae fused in the first two-thirds of the cell cycle (6-7 h); during the remainder of the cell cycle, the number of cells available to fuse presumably declined as an increasing number of cells entered mitosis. Comparison of the age distributions of fusing cells in the two types of culture was complicated by the fact that the amoebal IMT was significantly shorter in the mat $A$-heteroallelic mixtures than in all other cultures (Table $1 a$ ); this could have been a consequence of alterations in environmental conditions caused by the presence of developing plasmodia in $m a t A$-heteroallelic cultures. In $m a t A$-homoallelic cultures, a significant reduction in mean IMT was observed for cells which split apart after amoebal fusion but before undergoing mitosis (Table $1 a, e$ ); we can offer no explanation for this reduction.
In the sexual development of many organisms, cell fusion occurs in the Gl phase of the cell cycle, although there is evidence that Tetrahymena micronuclei are in the G2 phase at the time of cell fusion (Crandall, 1977; Doerder \& De Bault, 1975). Physarum amoebae, like plasmodia, apparently have no Gl phase in their vegetative cell cycle (Turner et al., 1981; Nygaard et al., 1960). We cannot exclude the possibility that mating occurred only during a Gl phase in Physarum, but if this was so, the mean length of time for which an amoeba must have remained in G1 prior to mating was $3.5 \mathrm{~h}$, about one-third of the length of an amoebal cell cycle (Fig. 3, Table 1). Such an extended G1 period seems unlikely since measurements of DNA content by flow cytometry indicate that there is no Gl peak in exponentially growing, clonal cultures (Fry \& Matthews, 1987); such cultures should contain a significant proportion of mating competent amoebae (Shipley \& Holt, 1982). If the cell cycle was normal in the mating populations that we observed, the amoebae must have been in the S or G2 phase at the time of cell fusion.

In agreement with the observations of Holt \& Huttermann (1979), the first evidence that plasmodium development had been initiated in the mat $A$-heteroallelic mixtures was the occurrence of nuclear fusion in interphase about $2 \mathrm{~h}$ after amoebal fusion; interphase nuclear fusion did not occur in mat $A$-homoallelic mixtures. There is evidence that microtubules have an essential function in nuclear fusion in Chlamydomonas and other organisms (Dutcher, 1988; Oakley \& Morris, 1980). Our immunofluorescence studies suggested that this might also be the case in Physarum, since changes in microtubule organization apparently began before nuclear fusion; although each member of a fusing pair of amoebae presumably contributed one MTOC to the fusion cell, two MTOCs were found in only $52 \%$ of $m a t A$ heteroallelic fusion cells and $3 \%$ of zygotes. In contrast, binucleate cells homoallelic for mat $A$ retained two clearly separate amoebal MTOCs and associated microtubules.

Comparison of the events in cell mixtures homoallelic and heteroallelic for mat $A$ revealed cellular events that were associated with mat $A$-heteroallelism: these included extension of the cell cycle, nuclear fusion in interphase, reduction in the number of MTOCs, and loss of ability to undergo the amoeba-flagellate transformation. These events were, therefore, directly or indirectly under the control of matA. Comparison of the events during sexual plasmodium formation with those previously described for apogamic plasmodium formation (Bailey et al., 1987) indicates which events are essential for development; nuclear fusion is clearly not essential since it did not occur in apogamic strains. A striking similarity between sexual and apogamic development, revealed by our present and previous (Bailey et al., 1987) 
filming analyses, is the existence of an extended cell cycle, approximately 2.3 times the length of an amoebal cell cycle, ending with the formation of a binucleate cell by mitosis without cytokinesis. This extended period may be essential for development and may be required for the completion of a series of developmentally regulated events leading to the onset of the plasmodial type of nuclear division cycle and the suppression of cytokinesis. The fact that apogamic strains arise as a result of mutations at mat $A$ reinforces our suggestion that extension of the cell cycle is under the control of mat $A$.

In sexual development, as was previously found in apogamic plasmodium formation (Bailey et al., 1987), the extended cell cycle was accompanied by continuing growth, leading to an increased cytoplasm:DNA ratio in the cell entering mitosis. In both types of development, following the extended cell cycle, there was a short cell cycle, about 0.7 times the length of an amoebal cell cycle, ending in the formation of a quadrinucleate cell. At the end of this short cell cycle, a sexually formed, diploid, quadrinucleate plasmodium was, on average, 11 times the mean area of an amoeba at birth. In the apogamic strain CL, a haploid, quadrinucleate plasmodium was approximately 6 times the mean area of an amoeba at birth (Bailey et al., 1987). These figures imply that the cytoplasm: DNA ratio, at this stage of development, was similar in both sexual and apogamic development. An increase and subsequent decrease in nuclear area occurred during the extended and shortened cell cycles in both sexual and apogamic development (Bailey et al., 1987). In contrast, in mat $A$-homoallelic fusion cells, there was no increase in the cytoplasm:DNA ratio; mitosis with cytokinesis occurred at the end of a period equivalent to the length of a normal amoebal cell cycle (Table $1 a, e$ ).

Our analysis of the timing of events in an apogamic strain (Bailey et al., 1987) showed that cells became committed to development during the extended cell cycle, at a maximum of $13.5 \mathrm{~h}$ (slightly more than one amoebal cell cycle) before binucleate cell formation. From kinetic studies, Shipley \& Holt (1982) suggested that, in sexual development, commitment to plasmodium formation coincided closely with the time of amoebal fusion and probably preceded nuclear fusion. The length of time between amoebal fusion and binucleate plasmodium formation, measured from our films, ranged from 13.6 to $20 \cdot 2 \mathrm{~h}$. Thus, if amoebal fusion coincides with commitment, binucleate plasmodium formation does not occur at a fixed time after commitment. There was a minimum interval of about 1.5 cell cycles between amoebal fusion and binucleate plasmodium formation; this interval could be related to the time required to complete a sequence of developmentally regulated events, including the time required to reach a minimum cell size for the mitosis by which the zygote becomes binucleate.

In apogamic development, the ability to undergo the amoeba-flagellate transformation was lost during the extended cell cycle, 3-5 $\mathrm{h}$ before commitment, at about the time that the cell would have divided had it continued to cycle vegetatively (Blindt et al., 1986; Bailey et al., 1987). Our immunofluorescence studies of sexual development showed that all fusion cells and some zygotes could transform into flagellates when suspended in water. Thus in sexual development, unlike apogamic development, cells are still able to transform into flagellates at about the time of, or even after, commitment; this is consistent with previous studies in which mating was observed between flagellates (Ross, 1957). However, no zygotes in mitosis or binucleate plasmodia were observed with flagella, indicating that ability to undergo the amoeba-flagellate transformation was lost by the time of binucleate plasmodium formation. In contrast, in mat $A$-homoallelic cultures, the majority of cells transformed into flagellates when suspended in water.

Even though many zygotes had two pairs of centrioles, very few of them possessed two long flagella. This agrees with observations on apogamic development which indicated that a change in centriolar function rather than a loss of centrioles was responsible for the loss of ability to undergo the amoeba-flagellate transformation and the failure to undergo amoebal mitosis (Blindt, 1987; Bailey et al., 1987). In some zygotes, the two pairs of centrioles did not show the close association with the MTOC that they have in amoebae (Fig. 9); this provides further evidence in support of the suggestion that a change in centriolar function occurred during the extended cell cycle in both apogamic and sexual plasmodium development (Blindt, 1987; Bailey et al., 1987).

The first observable change in microtubule organization detected by immunofluorescence studies of apogamic development occurred at the mitosis by which the developing uninucleate cell became binucleate; this mitosis appeared to be of the intranuclear plasmodial type (Blindt, 1987). Our films of sexual development suggested that the mitosis by which the zygote became binucleate might also be intranuclear since it resembled the mitosis observed in multinucleate plasmodia rather than mitosis in amoebae. Our immunofluorescence studies of sexual development showed that an extranuclear MTOC, presumably the remains of the amoebal MTOCs, was present in some zygotes at mitosis. In the following interphase, more binucleate plasmodia possessed two MTOCs than there were zygotes with two MTOCs, suggesting that the amoebal MTOC had duplicated even though it was not utilized during the first intranuclear plasmodial mitosis. The amoebal micro- 
tubule organization was lost only gradually over several cell cycles. Similar observations have been made on apogamic development (Gull et al., 1985; Blindt, 1987).

The isolation of diploid amoebae from mixtures of strains homoallelic for mat $A$ was first described by Youngman et al. (1981); such amoebae have been useful in genetic analysis by allowing dominance and complementation tests on mutants isolated in amoebae (Anderson \& Youngman, 1985; Dee et al., 1989). Holt \& Huttermann (1979) observed that nuclear fusion occurred at mitosis in binucleate fusion cells homoallelic for $m a t A$, and that cytokinesis gave rise to pairs of uninucleate, presumably diploid daughters. Youngman et al. (1981) found that the frequency of diploid amoebae formed in mat $A$-homoallelic mixtures was lower than the frequency of zygotes formed in mat $A$-heteroallelic cultures; to account for this difference they suggested that a minority of the fusion cells homoallelic for mat $A$ might split apart before mitosis. In our films of mat $A$ homoallelic cultures, the majority $(75 \%)$ of fusion cells were observed to split apart before mitosis and some cells underwent two or even three rounds of successive fusion and splitting.

Our filming studies also showed that even when a mat $A$-homoallelic fusion cell reached mitosis, this did not always lead to the formation of two diploid amoebae (Fig. 2, Table 2). Filming analysis indicated that putative diploid amoebae sometimes divided into three at mitosis, consistent with the observation of tripolar spindles in uninucleate cells during our immunofluorescence studies. The daughter cells from these divisions would presumably be aneuploid and would not be expected to survive; this may account for the reports that cultures of diploid amoebae have slower growth rates than cultures of haploid amoebae (Youngman et al., 1981).

The immunofluorescence studies showed that synchronous mitosis in mat $A$-homoallelic binucleate cells sometimes resulted in spindle fusion, although this involved only one pole of each spindle in some cases. Assuming that cytokinesis occurred at the equator of the spindle in each case (Rappaport, 1971), the different spindle orientations observed by immunofluorescence accounted for all the different types of products observed in the films (Figs 2 and 9). The occurrence of spindle fusion suggested that mitosis was of the amoebal type with breakdown of the nuclear envelope. Filming analysis of mat $A$-homoallelic cultures showed that mitosis was always followed by cytokinesis, indicating that the characteristic coupling of these events that occurs in amoebae had not been lost.

All the cellular events observed in mat $A$-homoallelic cultures can be explained by assuming that, although amoebal fusion occurred as a result of heteroallelism at $m a t B$ and $m a t C$, all the cells in the culture retained amoebal characteristics. Events associated with plasmodium development were observed only in cultures heteroallelic for matA, or in apogamic strains (Bailey et al., 1987), which are able to develop as a result of mutation at mat $A$. It is not clear which of these events is most closely related to the primary action of $m a t A$, and hence to the initiation of plasmodium development. Studies on mutants blocked at various stages of apogamic plasmodium formation, due to mutation at matA (Anderson et al., 1989) and at several other loci, will play an important part in elucidating the genetic control of plasmodium development.

We are grateful to the SERC for financial support (grant no. GR/D34530) and to Dr E. Orr (Leicester University) for use of the Zeiss Axiophot microscope. We also thank Ian Riddell and Kamlesh Chandarana for help with illustrations and Adrian Blindt and Keith Gull for helpful discussion.

\section{References}

ANDERson, R. W. \& Youngman, P. J. (1985). Complementation of $n p f$ mutations in diploid amoebae of Physarum polycephalum: the basis for a general method of complementation analysis at the amoebal stage. Genetical Research 45, 21-35.

ANDERSON, R. W., CoOKe, D. J. \& DeE, J. (1976). Apogamic development of plasmodia in Physarum polycephalum. Protoplasma 89, 29-40.

Anderson, R. W., Hutchins, G., Gray, A., Price, J. \& Anderson, S. E. (1989). Regulation of development by the mat $A$ complex locus in Physarum polycephalum. Journal of General Microbiology 135, 1347-1359.

Bailey, J., Anderson, R. W. \& DeE, J. (1987). Growth and development in relation to the cell cycle in Physarum polycephalum. Protoplasma 141, 101-111.

BLINDT, A. B. (1987). Changes in cellular organisation during apogamic development in Physarum polycephalum. PhD thesis, University of Leicester, Leicester, UK.

Blindt, A. B., Chainey, A. M., DeE, J. \& Gull, K. (1986). Events in the amoebal-plasmodial transition of Physarum polycephalum studied by enrichment for committed cells. Protoplasma 132, 149-159.

Blose, S. H., Meltzer, D. I. \& Feramisco, J. R. (1982). 10nm filaments induced to collapse in cells micro-injected with antibodies against tubulin. Journal of Cell Biology 95, 229a

CoOKE, D. J. (1974). Studies on the Colonia isolate of Phisarum polycephalum. PhD thesis, University of Leicester, Leicester, UK.

CoOKE, D. J. \& DEE, J. (1975). Methods for the isolation and analysis of plasmodial mutants in Physarum polycephalum. Genetical Research 24, 175-187.

Crandall, M. (1977). Mating-type interactions in micro-organisms. In Receptors and Recognition, vol. A3, pp. 45-100. Edited by P. Cuatrecasas \& M. F. Greaves. London: Chapman \& Hall.

DEE, J., Foxon, J. L. \& ANDERSON, R. W. (1989). Growth, development and genetic characteristics of Physarum polycephalum amoebae able to grow in liquid axenic medium. Journal of General Microbiology 135, 1567-1588.

Doerder, F. P. \& DE BAULT, L. E. (1975). Cytofluorimetric analysis of nuclear DNA during meiosis, fertilization and macronuclear development in the ciliate Tetrahymena pyriformis, syngen 1. Journal of Cell Science 17, 471-493.

Dutcher, S. K. (1988). Nuclear fusion-defective phenocopies in Chlamydomonas reinhardtii: mating-type functions for meiosis can act through the cytoplasm. Proceedings of the National Academy of Sciences of the United States of America 85, 3946-3950.

FRY, J. \& Matthews, H. R. (1987). Flow cytometry of the differentiation of Physarum polycephalum myxamoebae to cysts. Experimental Cell Research 168, 173-181. 
Gull, K., Birkett, C. R., Blindt, A. B., Dee, J., Foster, K. E. \& Paul, E. C. A. (1985). Expression of a multi-tubulin family and the in vivo assembly of microtubular organelles in Physarum polycephalum. In Microtubules and Microtubule Inhibitors, pp. 101-110. Edited by M. De Brabander \& J. De Mey. Amsterdam: Elsevier Science Publishers.

Havercroft, J. C. \& Gull, K. (1983). Demonstration of different patterns of microtubular organisation in Physarum polycephalum myxamoebae and plasmodia using immunofluorescence microscopy. European Journal of Cell Biology 32, 67-74.

Holt, C. E. \& HuttermanN, N. A. (1979). Genetic determination of plasmodium formation in Physarum polycephalum (Myxomycetes). Film B1337, Institut fur den Wissenschaftlichen Film, Göttingen, FRG.

Holt, C. E., Heunert, H., Huttermann, N. A. \& Galle, H.-K. (1979). Effect of mat A on nuclear fusion. In Abstracts of the 7th North American Physarum Meeting, August 1979, Quebec, Canada.

Howard, F. L. (1932). Nuclear division in plasmodia of Physarum. Annals of Botany 46, 461-477.

Kawano, S., Tsuneyoski, K. \& Anderson, R. W. (1987). A third multiallelic mating type locus in Physarum polycephalum. Journal of General Microbiology 133, 2529-2546.

NygaARD, O., GutTes, S. \& RusCh, H. P. (1960). Nucleic acid metabolism in a slime mould with synchronous mitosis. Biochimica et Biophysica Acta 36, 298-302.
OAKLEY, B. R. \& MORRIS, N. R. (1980). Nuclear movement is $\beta$ tubulin-dependent in Aspergillus nidulans. Cell 19, 255-262.

RAPPAPORT, R. (1971). Cytokinesis in animal cells. International Review of Cytology 31, 169-213.

Ross, I. K. (1957). Syngamy and plasmodium formation in the myxogastres. American Journal of Botany 10, 843-850.

ShIPLEY, G. L. \& Holt, C. E. (1982). Cell fusion competence and its induction in Physarum polycephalum and Didymium iridis. Developmental Biology 90, 110-117.

TANAKA, K. (1973). Intranuclear microtubule organizing centre in early prophase nuclei of the plasmodium of the slime mold Physarum polycephalum. Journal of Cell Biology 57, 220-224.

Turner, H. M., Mohberg, J. \& Goodman, E. M. (1981). A flow cytometry study of the cell cycle and of ploidy levels in Physarum polycephalum myxamoebae and plasmodia. Microbios 32, 29-36.

Youngman, P. J., Pallotta, D. J., Hosler, E., Struhl, G. \& Holt, C. E. (1979). A new mating compatibility locus in Physarum polycephalum. Genetics 91, 683-693.

Youngman, P. J., ANDERSON, R. W. \& Holt, C. E. (1981). Two multiallelic mating compatibility loci separately regulate zygote formation and zygote differentiation in the myxomycete Physarum polycephalum. Genetics 97, 513-530. 